\title{
Opportunistic Solvers Identification of a Crowdsourcing Innovation Platform
}

\author{
Jintong Hua ${ }^{1}$ Qingliang Meng ${ }^{1, *}$ \\ ${ }^{1}$ School of Management \& Economics, Jiangsu University of Science \& Technology, Zhenjiang, Jiangsu 212000, China \\ *Corresponding author. Email: mengzhi007@163.com
}

\begin{abstract}
Crowdsourcing innovation is characterized by loose organizational structures, free will of participants, strong innovation goals and information asymmetry, which can easily induce solvers' opportunistic behaviors, such as fraud, intellectual property theft, free-riding and so on. In order to create an attractive and supportive platform environment, identifying and avoiding opportunistic solvers is essential. In this study, a four-dimensional opportunistic solvers' identification system, including the work ability, the reputation level, the service level and the historical transaction level, is constructed. Then, the opportunistic solvers' identification model was proposed based on the PCA-BP neural network. The data is based on www.zbj.com, and taken into empirical research to verify the feasibility and effectiveness of the identification model.
\end{abstract}

Keywords: crowdsourcing innovation, opportunistic solvers, identification system, PCA-BP neural network

\section{INTRODUCTION}

Howe defines crowdsourcing as 'the act of a company or institution taking a function once performed by employees and outsourcing it to an undefined (and generally large) network of people in the form of an open call'. It has proved that this mode is an effective mode to acquire the wisdom of network groups[1]. InnoCentive brings more than 100,000 research talents from 125 countries around the world. So far more than 30,000 ideas has been submitted and 550 ideas has been implemented in Dell's IdeaStorm. However, as a new business model, the crowdsourcing innovation's related research is still in the exploratory stage. Therefore, the problem, such as solvers don't participate continuously[2] and low-quality of tasks[3]are more and more prominent.

The crowdsourcing is characterized by loose organizational form, solvers' free and voluntary will of participating and information asymmetry, which can easily lead to solvers' opportunistic behaviors, such as fraud, intellectual property theft. Hirth (2013) proposed two methods to monitor user fraud: majority decision-making and control group redetection[4]. Khasraghi (2014) pointed out that solvers' participation history has an important effect on their performance, such as the participation times and the winning rate[5]. Sun (2015) proposed that increasing speculative costs can effectively avoid opportunism solvers at the same time improve the bonus[6]. Ye (2017) summarized three threat forms of fraudulent solvers and proposed a threat defense model based on trust vector to avoid opportunistic behaviors of solvers[7]. Paswan (2017) pointed out that user fraud can be effectively restricted by applying the relational governance strategy and the role identification strategy[8].

Above researches have significance for identifying and limiting the opportunistic behaviors of solvers and ensuring the high-quality, sustainable development of the relationship the between platform and solvers. While, as a new business model, crowdsourcing innovation has complex and diverse innovation tasks, extensive sources of the public, and certain information asymmetry. In order to improve the relevant theories, reduce the risk of opportunistic behaviors and ensure the healthy development of crowdsourcing, it is necessary to make research on the opportunistic solvers identification from different perspectives.

\section{IDENTIFICATION SYSTEM}

Combined with the crowdsourcing platform www.zbj.com, this paper analyzes and summarizes 11 variables in four dimensions to build the opportunism solver identification system in crowdsourcing. As shown in Table 1 
Table 1. Opportunistic solvers' identification system in crowdsourcing innovation

\begin{tabular}{|c|c|c|c|}
\hline Dimension & $\begin{array}{c}\text { Inde } \\
\mathrm{x}\end{array}$ & Variable & Variable meaning \\
\hline \multirow{4}{*}{$\begin{array}{l}\text { Comprehensive } \\
\text { work ability }\end{array}$} & $X_{1}$ & Comprehensive score & $\begin{array}{l}\text { Comprehensive evaluation score of solvers on } \\
\text { crowdsourcing platform. }\end{array}$ \\
\hline & $X_{2}$ & Completion quality & $\begin{array}{l}\text { Score given by the employer for the quality of task } \\
\text { completion. }\end{array}$ \\
\hline & $X_{3}$ & Working speed & $\begin{array}{l}\text { Score given by the employer for the speed of solver's } \\
\text { submission. }\end{array}$ \\
\hline & $X_{4}$ & Solver level & Solver level on crowdsourcing platform \\
\hline \multirow{3}{*}{ Reputation level } & $X_{5}$ & Dispute rate & $\begin{array}{l}\text { Ratio of the tasks' number in dispute to total tasks } \\
\text { completed by this solver }\end{array}$ \\
\hline & $X_{6}$ & $\begin{array}{c}\text { Number of } \\
\text { punishments }\end{array}$ & $\begin{array}{l}\text { Number of times that solvers are punished by } \\
\text { crowdsourcing platform for dishonesty or violation }\end{array}$ \\
\hline & $X_{7}$ & Amount of deposit & $\begin{array}{l}\text { The amount of integrity deposit paid by solvers on the } \\
\text { crowdsourcing platform }\end{array}$ \\
\hline \multirow{2}{*}{ Service level } & $X_{8}$ & Service attitude & $\begin{array}{l}\text { Score given by the employer for the solver's service } \\
\text { attitude. }\end{array}$ \\
\hline & $X_{9}$ & Favorable rate & $\begin{array}{l}\text { Ratio of praised tasks to the total number of tasks } \\
\text { completed by solvers. }\end{array}$ \\
\hline \multirow{2}{*}{$\begin{array}{l}\text { Historical } \\
\text { transaction level }\end{array}$} & $X_{10}$ & Refund rate & $\begin{array}{l}\text { Ratio of the number of tasks refunded by solvers to the } \\
\text { total number of tasks completed by solvers. }\end{array}$ \\
\hline & $X_{11}$ & $\begin{array}{l}\text { Project completion } \\
\text { rate }\end{array}$ & $\begin{array}{l}\text { Ratio of the volume of completed orders to winning orders } \\
\text { in the past year. }\end{array}$ \\
\hline
\end{tabular}

\section{METHODOLOGY}

Considering that the opportunistic solvers' identification system contains multiple dimensional indicators, there may be some correlations among the variables, and resulting in information overlaps. Moreover, too many input layers will cause low learning efficiency, slow convergence speed and local minimum state of neural network. Therefore, this paper uses principal component analysis (PCA) to process the index data, which reduces the dimension of data and retains most of the original data[9]. The structure of neural network is simplified, and the input layers is reduced, and the convergence speed and performance are improved, so that the recognition accuracy is ensured. The principal component analysis (PCA) method simplifies the original data structure, and it uses fewer principal components to replace the complicated original variables, to make the problem clearer. The PCA-BP network model structure is shown in Fig. 1.

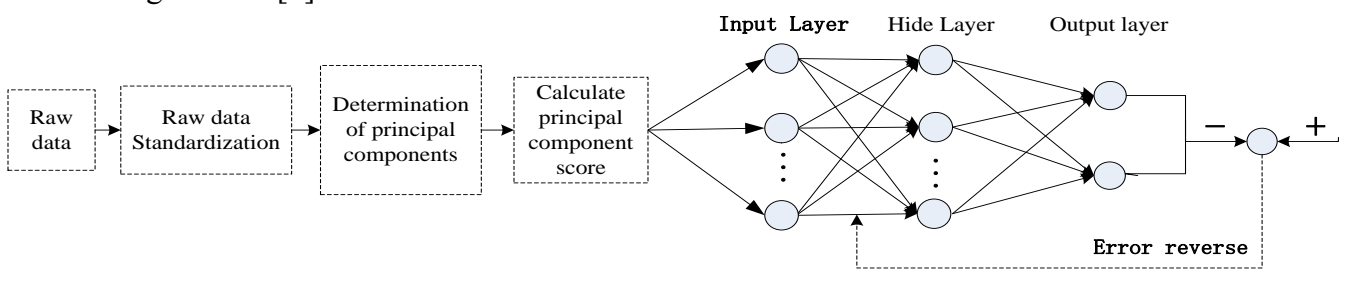

Figure. 1. The structure of PCA-BP neural network

\section{EMPIRICAL RESEARCH}

\subsection{Data collection}

www.zbj.com is the largest crowdsourcing platform in China, and its main services includes brand design, marketing promotion, website construction. This paper is based on the data of "Exposure Channel " column of integrity management center in www.zbj.com from August 2018 to April 2019. A total of 184 original data are collected, there are 34 opportunistic solvers and 150 normal solvers among the data. The main manifestations of opportunism are inducing or coercing the employer to evaluate, inability to complete tasks, manuscript plagiarism and failure to accomplish duties. The punished solvers mainly involves in brand design, website construction, e-commerce design services. Among 184 sample data, 154 data are taken as training set and 30 data as the testing set for empirical research.

\subsection{Data analysis}

Table 2 shows that the cumulative variance contribution rate of the first three principal components is $81.873 \%$. This shows that the first three principal components had already contains most of the information of the original variables. 
Table 2 Total variance explained

\begin{tabular}{|c|c|c|c|c|c|c|c|c|c|}
\hline \multirow[t]{2}{*}{ Component } & \multicolumn{3}{|c|}{ Initial Eigenvalues } & \multicolumn{3}{|c|}{$\begin{array}{c}\text { Extraction Sums of Squared } \\
\text { Loadings }\end{array}$} & \multicolumn{3}{|c|}{$\begin{array}{c}\text { Rotation Sums of Squared } \\
\text { Loadings }\end{array}$} \\
\hline & Total & $\begin{array}{c}\% \text { of } \\
\text { Variance }\end{array}$ & $\begin{array}{c}\text { Cumulativ } \\
\mathrm{e} \\
\%\end{array}$ & Total & $\begin{array}{c}\% \text { of } \\
\text { Variance }\end{array}$ & $\begin{array}{c}\text { Cumulativ } \\
\mathrm{e} \\
\%\end{array}$ & Total & $\begin{array}{c}\% \text { of } \\
\text { Variance }\end{array}$ & $\underset{\%}{\text { Cumulative }}$ \\
\hline 1 & 5.415 & 49.224 & 49.224 & $\begin{array}{c}5.41 \\
5 \\
\end{array}$ & 49.224 & 49.224 & $\begin{array}{c}5.22 \\
4\end{array}$ & 47.492 & 47.492 \\
\hline 2 & 2.572 & 23.38 & 72.604 & $\begin{array}{c}2.57 \\
2\end{array}$ & 23.38 & 72.604 & $\begin{array}{c}2.26 \\
2\end{array}$ & 20.566 & 68.058 \\
\hline 3 & 1.02 & 9.269 & 81.873 & 1.02 & 9.269 & 81.873 & 1.52 & 13.815 & 81.873 \\
\hline 4 & 0.749 & 6.808 & 88.681 & & & & & & \\
\hline 5 & 0.587 & 5.339 & 94.021 & & & & & & \\
\hline 6 & 0.398 & 3.617 & 97.637 & & & & & & \\
\hline 7 & 0.141 & 1.278 & 98.915 & & & & & & \\
\hline 8 & 0.074 & 0.67 & 99.585 & & & & & & \\
\hline 9 & 0.024 & 0.215 & 99.801 & & & & & & \\
\hline 10 & 0.013 & 0.119 & 99.92 & & & & & & \\
\hline 11 & 0.009 & 0.08 & 100 & & & & & & \\
\hline
\end{tabular}

Table 3 Rotated Component Matrixa

\begin{tabular}{cccc}
\hline & \multicolumn{3}{c}{ Component } \\
\cline { 2 - 4 } & 1 & 2 & 3 \\
\hline comprehensive score & 0.983 & -0.108 & -0.056 \\
\hline completion quality & 0.97 & -0.142 & -0.053 \\
\hline working speed & 0.975 & -0.116 & -0.067 \\
\hline solver level & 0.29 & 0.524 & 0.576 \\
\hline dispute rate & -0.153 & 0.897 & -0.267 \\
\hline number of punishments & -0.18 & 0.756 & -0.287 \\
\hline amount of deposit & 0.317 & 0.433 & 0.68 \\
\hline service attitude & 0.982 & -0.104 & -0.108 \\
\hline favorable rate & 0.959 & -0.057 & -0.062 \\
\hline refund rate & 0.569 & 0.492 & -0.149 \\
\hline project completion rate & 0.334 & 0.657 & -0.155 \\
\hline
\end{tabular}


Table 4 Component Score Coefficient Matrix

\begin{tabular}{cccc}
\hline & \multicolumn{3}{c}{ Component } \\
\cline { 2 - 4 } & 1 & 2 & 3 \\
\hline comprehensive score & 0.983 & -0.039 & 0.119 \\
\hline completion quality & 0.973 & -0.07 & 0.104 \\
\hline working speed & 0.977 & -0.041 & 0.105 \\
\hline solver level & 0.111 & 0.219 & 0.793 \\
\hline dispute rate & -0.216 & 0.916 & 0.12 \\
\hline number of punishments & -0.22 & 0.798 & 0.036 \\
\hline amount of deposit & 0.131 & 0.092 & 0.851 \\
\hline service attitude & 0.99 & -0.011 & 0.075 \\
\hline favorable rate & 0.953 & 0.009 & 0.131 \\
\hline refund rate & 0.519 & 0.526 & 0.206 \\
\hline project completion rate & 0.27 & 0.667 & 0.22 \\
\hline
\end{tabular}

As shown in table 3 , in the principal component 1, the load of comprehensive score, completion quality, working speed, service attitude, favorable rate and refund rate are large, which represents the solver's comprehensive quality in the process of completing tasks. In principal component 2 , dispute rate, the number of punishments and project completion rate have a large load, which could represent the opportunistic tendency of solvers in the process of communication and transaction. In principal component 3, solver level and the amount of deposit are large, which could represent the level of solver in crowdsourcing platform. It is generally true that the higher the level of solver, the more deposit they pay.

The scores of three principal components are calculated by formula (1), then there will be the input variables of BP neural network.

$$
\left\{\begin{aligned}
F_{1}= & 0.983 Z x_{1}+0.973 Z x_{2}+0.977 Z x_{3}+0.111 Z x_{4}-0.216 Z x_{5}-0.22 Z x_{6} \\
& +0.131 Z x_{7}+0.99 Z x_{8}+0.953 Z x_{9}+0.519 Z x_{10}-0.27 Z x_{11} \\
F_{2}= & -0.039 Z x_{1}-0.07 Z x_{2}-0.041 Z x_{3}+0.219 Z x_{4}+0.916 Z x_{5}+0.798 Z x_{6} \\
& +0.092 Z x_{7}-0.011 Z x_{8}+0.009 Z x_{9}+0.526 Z x_{10}+0.667 Z x_{11} \\
F_{3}= & 0.119 Z x_{1}+0.104 Z x_{2}+0.105 Z x_{3}+0.793 Z x_{4}+0.12 Z x_{5}+0.036 Z x_{6} \\
& +0.851 Z x_{7}+0.075 Z x_{8}+0.131 Z x_{9}+0.206 Z x_{10}+0.22 Z x_{11}
\end{aligned}\right.
$$

\subsection{Results contrast}

In this paper, the original variables are synthesized into three principal components by PCA and the scores of each principal component are obtained. 184 data are divided into training data and testing data according to the ratio of nearly 10:2, which are used for training and testing of BP neural network. There are 154 training data, including 23 opportunistic solvers and 131 normal solvers; 30 testing data, including 10 opportunistic solvers and 20 normal solvers. The BP neural network model is trained by training data, and the setting error is achieved at step 4552. The error curve is shown in Fig.2.

PCA-BP neural network model is used for recognition, with 27 correct and 3 wrong identifications, and the recognition accuracy is $90 \%$; The recognition results of traditional BP neural network are 23 correct and 7 wrong, the recognition accuracy is $76.7 \%$. Therefore, the BP neural network model improved by PCA method have higher recognition accuracy.

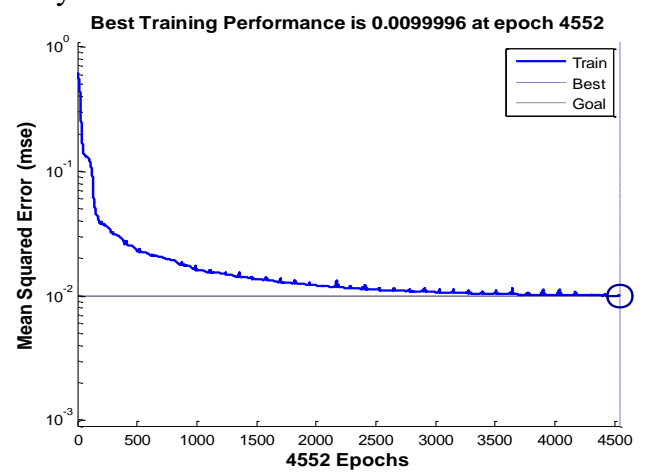

Figure. 2. The error curve graph

\section{DISCUSSION}

Based on the above theoretical analysis and empirical results, this paper proposes three strategies to avoid the opportunistic behavior of solvers.

(1) Setting up a scientific opportunistic solvers' identification mechanism. The identification methods of opportunistic solvers in crowdsourcing innovation are mostly post-test methods, that is, to evaluate the quality of submitted tasks or to identify the accused solvers. Therefore, it is necessary to set up a reasonable opportunistic solvers' identification mechanism to transform the post-event control into process identification. According to the solver's past historical data and participation information, it is effective to identify the solvers with higher opportunistic tendency, and improve 
[2] Wexler, M, Reconfiguring the sociology of the crowd: exploring crowdsourcing, International Journal of Sociology and Social Policy.31(1-2) (2011) 6-20. DOI: https: //doi.org/10.1108/01443331111104779

[3] Boudreau K J, Lakhani K R, Using the Crowd as An Innovation Partner, Harvard Business Review.91(4) (2013)60-9, 140.D OI: http: //doi.org/10.1080/08985626.2012.721008

[4] Hirth M, Hoßfeld T, Analyzing Cost Sand Accuracy of Validation Mechanisms for Crowdsourcing Platforms, Mathematical \& Computer Modelling.57(11-12) (2013) 2918-2932. DOI: http: //doi.org/10.1016/j.mcm.2012.01.006

[5] Khasraghi H J, Aghaie A, Crowdsourcing Contests: Understanding the Effect of Competitors' Participation History on Their Performance, Behaviour \& Information Technology. 33(10-12) (2014)1383-1395. DOI: http: //doi.org/10.1080/014492 9x.2014.883551

[6] Sun Y, Wang N, Yin C, et al, Understanding the Relationships Between Motivators and Effort in Crowdsourcing Marketplaces: A Nonlinear Analysis, International Journal of Information Management. 35(3) (2015) 267-276. DOI: http: //doi.org/10.1016/j.ijinfomgt.2015.01.009

[7] B. Ye, Y. Wang and L. Liu, Crowd Defense: A Trust Vector-Based Threat Defense Model in Crowdsourcing Environments, in: IEEE International Conference on Web Services (ICWS), Honolulu, HI, 2017, pp. 245252. DOI: http://doi.org/10.1109/ICWS.2017.39

[8] Paswan A K, Hirunyawipada Tanawat, Iyer P, Opportunism, Governance Structure and Relational Norms: An Interactive Perspective, Business Research.77(2017) 131-139. DOI: http://doi.org/10.1016/j.jbusres.2017.04.012

[9] Esbensen K H, Geladi P, 2.13 - Principal Component Analysis: Concept, Geometrical Interpretation, Mathematical Background, Algorithms, History, Practice, Comprehensive Chemometrics. (2009) 211-226. DOI:http://doi.org/10.1016/B978-044 452701-1.00043-0
This work was supported by Foundation of Humanities and of China No. 19YJA630055; Postgraduate Research \& Practice Innovation Program of Jiangsu Province No. KYCX19-1652.

\section{REFERENCES}

[1] Lang M, Bharadwaj N, How crowdsourcing improves prediction of market-oriented outcomes, Business Research.69 (10) (2016) 4168-4176. DOI: http: //doi.org/10.1016/j.jbusres.2016.03.020 